\title{
The puzzle of high political partisanship among ethnic minority young people in Great Britain
}

DOI:

10.1080/1369183X.2018.1539285

\section{Document Version}

Accepted author manuscript

Link to publication record in Manchester Research Explorer

\section{Citation for published version (APA):}

Martin, N., \& Mellon, J. (2018). The puzzle of high political partisanship among ethnic minority young people in Great Britain. Journal of Ethnic and Migration Studies. https://doi.org/10.1080/1369183X.2018.1539285

\section{Published in:}

Journal of Ethnic and Migration Studies

\section{Citing this paper}

Please note that where the full-text provided on Manchester Research Explorer is the Author Accepted Manuscript or Proof version this may differ from the final Published version. If citing, it is advised that you check and use the publisher's definitive version.

\section{General rights}

Copyright and moral rights for the publications made accessible in the Research Explorer are retained by the authors and/or other copyright owners and it is a condition of accessing publications that users recognise and abide by the legal requirements associated with these rights.

\section{Takedown policy}

If you believe that this document breaches copyright please refer to the University of Manchester's Takedown Procedures [http://man.ac.uk/04Y6Bo] or contact uml.scholarlycommunications@manchester.ac.uk providing relevant details, so we can investigate your claim.

\section{OPEN ACCESS}




\title{
The puzzle of high political partisanship among ethnic minority young people in Great Britain
}

Nicole Martin and Jonathan Mellon (University of Manchester)

\begin{abstract}
Previous studies have found that ethnic minorities in Britain have similar levels of partisan attachment as white UK respondents. However, we find that this hides substantial ethnic differences in levels of partisanship within age groups (minorities are younger on average) and that there is a substantial minority party attachment premium that is widest for the youngest respondents. Our paper therefore examines the factors that account for the substantial partisanship gap between minority and white UK respondents by the time they enter the electorate. Using waves 3, 5 and 7 (2011-2016) of the Understanding Society youth panel, which follows 10-15 year olds in the UK, we model both the early attainment of party attachment among respondents (the first time we observe them as part of the youth panel) and the subsequent retention of this party attachment up to age 15, or acquisition of party attachment among young people who had not attained partisanship at the time of first observation. We find that differences in levels of parental partisanship and political engagement are the key factors in explaining the difference in minority and white UK acquisition and retention of party attachment during this critical period of political development.
\end{abstract}

Keywords: ethnicity, party attachment, young people, politics, partisanship.

\section{Introduction}

The last five decades have seen a substantial decline in British voters' attachment to political parties, with new generations of voters less and less likely to describe themselves as identifying with a political party and more likely to switch between parties (Fieldhouse et al., 2018). Importantly, this dealignment is not distributed uniformly across the population. Previous work has found that party identification levels are similar among minority and white UK populations overall (Heath et al., 
2013). However, researchers have not tested whether this lack of difference between minority and majority partisanship holds within age groups. Using wave 3 of the Understanding Society adult faceto-face interview (2011-2011 data collection), in Figure 1 we find that there is in fact a substantial gap in having a party preference between young minority and white UK adults, with the gap only closing for the oldest respondents. This age gradient in party preference among white UK adults is consistent with Dalton (1984) who find this for many countries including Britain. The lack of an overall difference in party attachment is driven by the fact that young people constitute a smaller proportion of the white UK population than British minorities. ${ }^{1}$

\section{[FIGURE 1 ABOUT HERE]}

This paper therefore asks how minority voters have resisted the trend towards ever lower attachment to parties. Since the ethnic gap is already present (and indeed largest) by the time minority voters enter the electorate, we need to look earlier in order to understand how these differences emerge. We make use of Understanding Society, a representative household panel study of the UK, in order to understand the process of ethnic minority young people gaining a party identity and how this differs from white UK young people. We achieve this by focussing on an important period of political socialisation from age 10 to 15 , looking both at both the acquisition of partisanship as of a respondent's first observation during this period (early socialisation), and the acquisition or retention of party identity in subsequent waves.

Our principal argument is that a meaningful amount of the gap in party identity acquisition between minority respondents and the white UK population can be explained by the stronger partisan attachments of the parents of minority respondents and parents' adoption of participatory norms and political engagement. Our analysis gives only limited evidence for social capital as an explanation for the party attachment gap. We therefore conclude that ongoing minority attachment to political parties is largely attributable to minority voters being raised in households where the parents have strong

\footnotetext{
${ }^{1}$ The size of this gap depends somewhat on the data source and question wording used. Out of using different combinations of the two party attachment questions on Understanding Society and either waves 1 or 3 of the data, as well as the party identity wording on the Ethnic Minority British Election Study/British Election Study, we find the pattern of a substantial party attachment gap between younger minority and white UK respondents and a steeper age gradient of party attachment for white UK respondents in four out of the five comparisons.
} 
attachments to a political party, hold participatory norms and have a strong interest in politics. While the rest of the population has become more indifferent between Labour and the Conservatives as the parties converged towards the centre after 1994 (Evans and Tilley, 2017), minority voters still maintain strong attachments to the parties (particularly Labour) and socialise their children accordingly. Ethnic minority voters are therefore not so different to white UK voters in the way they socialise their children or develop political identities. Instead minorities primarily differ in having strong views about the parties to pass down to their children at all.

\section{Theory}

\section{Ethnic minority partisanship}

High levels of Labour partisanship among ethnic minorities are an enduring feature of British politics (Anwar, 1986; Saggar and Heath, 1999; Back and Solomos, 2002; Heath et al., 2013) - but previous work has neglected to explicitly examine differences between age groups, instead focussing on immigrant generation, and controlled for age as a linear predictor without substantively examining it. Our paper fills a gap in this literature by (i) considering in more detail how the age gradient differs between minorities and the white UK population, and (ii) examining party attachment among young people. Although Heath et al. (2013) mention the gap in Labour support between minority and white UK young people (p.118), they do not discuss the overall partisanship gap between young people. Our contribution is in pointing out that by being more supportive of Labour more generally, ethnic minority young people exhibit a stronger attachment to parties in general than white UK young people. This phenomenon has been overlooked by scholarship on the decline of young people's partisanship (Mellon, 2016).

Given the predominance of the Labour party among minority voters, explanations of partisanship per se have not been differentiated from explanations of Labour partisanship. Heath et al. (2013) argue that ethnic minority Labour partisanship is best thought of in a sociotropic context. Drawing heavily on Dawson's theory of linked fate (Dawson, 1994), they argue that perceptions of how well the Labour party has protected ethnic minority group interests are the key explanation for 
the strong predominance of Labour partisanship. They point out that in 2010, the Labour party were responsible for all race and religious equality legislation implemented in UK, and link individual and group perceptions through multi-level analysis of partisanship. In this issue, Nandi and Platt (Nandi and Platt, 2018) show that discrimination shapes ethnic minorities' political identity. This approach has some similarities to approaches to partisanship that emphasise the social identity aspect of partisanship (Green, Palmquist and Schickler, 2002), where partisan labels become part of a voter's self-conception. However, proponents of linked fate would argue that (perceived) material interests and deprivation are a key component of minority partisanship - the difference is that parties are judged on their success at promoting the in-group's interests, rather than the individual's (Wilson, 2012).

Consequently, Heath et al. (2013) reject an individualistic Downsian explanation for minorities' partisanship. There have always been some significant differences in issue positions between ethnic minority voters and the Labour party, but strong support for Labour endures during those differences. For instance, although many Muslim voters disagreed with the war in Iraq enough to change their vote choice on account of this in 2005, this effect unwound in 2010 and 2015 with Muslim voters returning to the Labour party. Moreover, there is little stratification of ethnic minority partisanship by social class (Saggar and Heath, 1999; Martin, 2016), which is a strong predictor of partisanship in the white UK population.

A different approach to partisanship argues that it is simply a running tally of a voters' experiences with the parties, where voters judge the parties based on their past actions and therefore become relatively unlikely to move after they have observed the parties for a particular length of time (Fiorina, 1981). However, Heath et al. argue that a running tally account cannot explain minority Labour partisanship, because it is just as strong among young people who have only experienced one or two elections as it is among older people who have experienced more elections, during which the dividing lines between Labour and the Conservatives on race and immigration were even starker.

The importance of group interests in explaining ethnic minority partisanship is relevant to our focus on the socialisation of young people in two ways. Firstly, if ethnic minority partisanship is based on group interests, this norm of behaviour must be communicated to young people in some 
way. Young people who are becoming aware of politics will be socialised by these discussions and social norms. Secondly, that failure of the running tally approach (because young minority voters are just as supportive of Labour as their older counterparts) implies that this the experiences that sustain Labour partisanship happen before young people enter the electorate. This is why we choose to focus on how ethnic minority young people pick up and reproduce the partisan attachments of their parents.

\section{Socialisation}

Socialisation is the process by which individuals internalise norms of a community. Previous studies have looked at the socialisation of party identity and other political attitudes from a number of directions. Tilley found that there were substantial socialisation effects visible across generations, with young people more likely to adopt the partisanship of the party that was in power when they came of age (Tilley, 2002). Similarly, cohort effects have been attributed to socialisation regarding authoritarian attitudes and the party of government in recent research (Grasso et al., 2017).

There are broadly two sets of reasons why young people might differ in their levels of socialisation into a norm. First, there may be fewer efforts by other people to socialise the young person into the norm. This could be because the other people in the young person's life hold the norm less strongly or not at all and therefore have a different desire to socialise the young person. Second, it may be the case that the socialisation processes themselves are more or less effective for a variety of reasons.

There are a number of reasons why individuals may have different desires to socialise a party identity. Most importantly a young person's parents may not hold a norm or belief such as party identity or may not feel strongly about the importance of that identity. This has clearly played a role in the lowered rate of socialisation into religious faith in various western societies. As religion becomes less important to the lives of individuals, they are less likely to feel the need to make efforts to socialise their children into their religion and the surrounding institutions and rituals (McAndrew and Voas, 2014). In the case of party identity, the most obvious source of socialisation pressures are a young person's parents. Since minority voters have long had a strong attachment (especially to the 
Labour party) (Heath et al., 2013), we would expect that minority parents would have a greater desire to socialise their children.

There are also other possible socialisation sources. Minority groups in Britain often interact disproportionately within their own ethnic group (Heath et al., 2013), and therefore may be exposed to uniformly partisan messages within these groups. Examples of this so-called bonding social capital are coethnic voluntary organisations (Fennema and Tillie, 1999; Heath et al., 2013), faith groups and religious leaders (Calhoun-Brown, 1996; Akhtar, 2012; Sobolewska et al., 2015), and the proportion of coethnic residents in the neighbourhood (Fieldhouse and Cutts, 2008b), which have all been associated with greater political participation and engagement of ethnic minorities. It is also the case that minorities live in disproportionately Labour areas which may be more conductive to engendering partisanship in young people (who are disproportionately likely to support Labour if they do develop partisanship). Understanding Society data shows that $63 \%$ of adults from an Indian, Pakistani, Bangladeshi, black Caribbean or black African background during 2013-2014 lived in a seat that Labour won in the 2015 general election; only $31 \%$ of white UK adults did so.

While the desire may be present to socialise, there are many factors that may affect whether this socialisation will be successful. The first factor that we consider that may affect socialisation success is whether their children receive consistent or mixed messages about the parties. As the party system fragmented (up until 2017 when there was a startling reversal), more families are likely to consist of parents with conflicting party identifications. This means that children will receive mixed messages about what norm to adopt because more parents will have different opinions - at least in terms of which party to form an attachment to. However, mixed messages may not necessarily reduce levels of identity if the norm being transmitted is one of interest and engagement with politics. For instance Dinas (2013) reports that children who are socialised into the political views of their parents are also more likely to later lose these views as a result of their greater engagement with political events. Similarly (Fieldhouse and Cutts, 2016) do not find that opposing partisanship suppresses household turnout.

\section{Compositional effects}


Minority groups in Britain have substantially different social and economic characteristics. Overall, minorities are more likely to have strong religious beliefs and practice (Crockett and Voas, 2006; Van Tubergen and Sindradóttir, 2011), have working class jobs (Heath and Cheung, 2006), and live in urban (ONS, 2013) and/or deprived areas (Jivraj and Khan, 2013). Additionally minority children now perform better than white UK children in school (with some exceptions) and are more likely to participate in higher education (Dustmann, Frattini and Theodoropoulos, 2010; Burgess, 2014). It may therefore be the case that one of these social characteristics is independently related to higher levels of party attachment either directly for the children themselves or via their parents. For instance, religious and higher education institutions may provide another socialisation avenue for young people. However, the greater preponderance of working class occupations is unlikely to explain higher party attachment among minorities, as working class voters have been the group most likely to grow disengaged with politics during the last few decades (Heath, 2016; Evans and Tilley, 2017).

\section{Summary}

Our aim in this paper is to explain the greater levels of party identity that we have found among ethnic minority young people, compared to white UK young people. In order to do this, we focus on young people's party attachment at an early and formative age, when they are being socialised into group norms of many kinds, including political partisanship. There are three broad potential explanations that we consider. Firstly, we expect that the household partisan composition of young people might explain part of the gap; firstly, ethnic minority 10-15 year olds might be more likely to grow up in a household where both parents or at least one have a party identity, and secondly ethnic minority parents might be less likely to disagree on partisanship, due to the higher overall levels of support for one party (the Labour party). Ethnic minority young people might also be socialised in a household with stronger participatory norms or interest in politics. A second potential explanation is that ethnic minority young people are exposed to more partisan socialisation due to bonding social capital - the tendency of people to spend more time within their own social group. Our third avenue of investigation is whether socioeconomic variables explain or moderate the gap in party attachment 
between ethnic minority and white UK young people. The next section describes our choice of data and modelling strategy in detail.

\section{Data and Methods}

Understanding Society is a nationally representative household panel study of the UK (Knies, 2017).

The fieldwork for the first wave was in 2009-10 and participants are interviewed annually. This paper includes the General Population Sample (GPS) and the Ethnic Minority Boost (EMB) sample (that was sampled from areas where at least $5 \%$ of the population was from an ethnic minority background in the 2001 Census). Ethnic minorities in low-density areas are also represented in the data, as they are included in the GPS. For further details about the survey see the Introduction of this Special Issue (Platt and Nandi 2018).

We use data from two survey instruments. For information on young people's party attachment, we use the youth questionnaire which is fielded each wave as a paper self-completion questionnaire that is given the 10-15 year olds in responding households. The youth questionnaires in Waves 3,5 and 7 contain two questions on politics; the party attachment question described below, and a question on political interest. For information on the household context of young people, we use data from adult interviews (administered to 16+) with their parents. These were face-to-face interviews with self-completion components .

When it comes to contextual information on young people, mother's data is more readily available - most young people live with their mother, but not all live with their father. In our data $70 \%$ of young people live with their father, compared to $97 \%$ who live with their mother. $69 \%$ of young people who live with their mother also live with their father; but $96 \%$ of those who live with their father also live with their mother. In exploratory modelling which included both mother's and father's characteristics, it was mostly the mother's characteristics that were significantly correlated with the outcome variable, so we have tended to include mother's characteristics.

\section{Measuring party attachment}


Our key dependent variable for young people is party attachment. We measure this using the question: 'If you could vote for a political party, which one would you vote for?'

Respondents can answer the question with a party, say 'don't know' or skip the question. We code non-identifiers based on those who say none or don't know, as well as those who skip the question but answer surrounding questions.

The adult questionnaire uses a slightly different party attachment question to the general Understanding Society sample, which means that we cannot directly track changes in party attachment between early adolescence and adulthood. The youth question is not precisely a measure of party identity, but we think it does stand in as a measure of party attachment more broadly. Previous research has shown that while the different party identity questions record radically different levels of party identity, the trends in these questions tend to track each other closely and that the different questions can probably be thought of as tapping the same underlying construct but at different levels (Fieldhouse et al., 2018), although they are certainly not perfect substitutes (Sanders, Burton and Kneesaw, 2002; Bartle, 2003).

\section{Measuring party images}

In addition to parental attachment to parties, we also analyse other measures of how young people's parents relate to the political parties. We use measures from the adult questionnaire of how much each parent likes or dislikes Labour and the Conservatives. As well as knowing how much the parent likes each of the parties, we can also measure how much of a gap there is between how much the parents like each party. In other words, a measure of how indifferent they are between the two parties. As the major parties converged towards the centre in the past two decades, increasing numbers of voters report that they do not believe that there is a major difference between Labour and the Conservatives (Fieldhouse et al., 2018). However, we know from previous research that minorities see Labour and the Conservatives as particularly differentiated on issues such as support for black and Asian interests (Heath et al., 2013). If the parents of minority young people have more differentiated preferences regarding the major parties, this is another view that they may pass on to their children. 


\section{Measuring ethnicity}

We consider ethnicity primarily based on a respondent's self-identification. Where this is not available, we make us of parental ethnicity data, as this is highly correlated with self-identified ethnicity for respondents where we have access to the young person and parents' ethnic identities. If we do not have self-reported data about a young person's ethnic identity, we first use the combination of their parents' self-reported ethnic identities to infer the child's. If only one parent has available ethnicity data, we use just this parent's ethnicity. Among those where we observe their own ethnicity or that of both parents, using mother's ethnicity instead of combined information or young person's information would correctly classify $72 \%$ of respondents. Table 1 shows the distribution of ethnicities in the young person sample we use in this paper. While the sample is majority white UK, we have young people from the five established ethnic minority groups in Britain - Indian, Pakistani, Bangladeshi, black Caribbean, and black African. Further descriptive statistics concerning our samples can be found in the appendix.

The minorities in our sample are mostly second generation (parents immigrated to Britain) or at least 1.5 th generation (the respondent immigrated to Britain at a young age). This is important because any comparison between minorities and the white UK is comparing people who were politically socialised in Britain with those whose adolescence's were spent abroad. By looking instead at 10-15 year olds, we are comparing young people who are all undergoing secondary schooling in the same country. Given our interest in the process of political socialisation, we believe this is closer to comparing like with like than if we were to study partisan differences between 20-30 year olds, some of whom were socialised abroad and some in the UK.

Table 1: Proportion of ethnic and age groups with party attachment, weighted (youth questionnaire).

\begin{tabular}{rrr}
\hline Ethnic group: & \% with party attachment & Number of observations \\
\hline white UK & $44 \%$ & 3,945 \\
white other & $36 \%$ & 104 \\
Indian & $56 \%$ & 115 \\
Pakistani & $62 \%$ & 134 \\
Bangladeshi & $67 \%$ & 35 \\
black Caribbean & $71 \%$ & 35 \\
black African & $64 \%$ & 101 \\
mixed & $55 \%$ & 346 \\
\hline
\end{tabular}




\begin{tabular}{|c|c|c|}
\hline Age: & & \\
\hline 10 & $43 \%$ & 1,145 \\
\hline 11 & $42 \%$ & 1,123 \\
\hline 12 & $48 \%$ & 732 \\
\hline 13 & $49 \%$ & 629 \\
\hline 14 & $55 \%$ & 608 \\
\hline 15 & $49 \%$ & 579 \\
\hline
\end{tabular}

\section{Modelling Approach}

Table 1 also shows the weighted proportion of Understanding Society respondents taking the young person survey who express a party attachment at each age. As expected, we see significant gains in party attachment during respondents' experiences at ages $10-15$, confirming that it is an important period of political development for young people. Nonetheless, this still leaves $43 \%$ of respondents who already have attained a party identification by age 10 . We therefore focus on modelling (i) the cross-sectional attainment of party attachment across this sample and (ii) the attainment/retention of party attachment among respondents from ages 10-15.

In our cross-sectional models, we use logistic regression to predict whether a respondent has a party attachment when they enter the sample. This approach attempts to model what explains variation in respondents' levels of party attachment when they are first observed. We then model transitions between having and not having a party attachment among these respondents. Because we suspect the predictors of gaining a party identity may be different to the predictors of losing a party identity, we run separate logistic regression models on respondents who had a party attachment at the time of their first observation and those who did not have one.

The cross-sectional analysis uses pooled data from waves 3 and 5 of Understanding Society. Standard errors are adjusted for clustering and stratification in the sample design, and weights are used to account for design effects, non-response and attrition. The unweighted sample size for this pooled data set is 4,579 young people with a valid response for all variables used in our models.

Secondly, we use two-wave panels to model (using logistic regression) both the acquisition of party attachment among those who previously did not report one, and its persistence among those who previous did have one. These use pooled data from waves 3-5, and waves 5-7. The party attachment question is asked with a gap of two years, and respondents are only eligible when they are aged 10-15 
years. As respondents who were aged 14 or 15 at the first time point are no longer eligible at the second, and those who are aged 10 or 11 at the second time point were not eligible at the first, the number of repeat observations is much smaller than the cross-sectional sample. For these reasons, the analysis of transitions should be interpreted as a test of internal validity, rather than something that is generalizable to the population as a whole. For those who did not have a party attachment at the previous time point, the total weighted number of individuals in these two wave panels is 1,441 , of which 192 appear twice. For those who did have a party attachment at the previous time point, the total number of individuals in these two wave panels is 1,106 , of which 135 appear twice. This analysis pools data from waves 3,5 and 7 .

The first model of each set is restricted to those who did not have a party attachment at the previous time point i.e. it looks at whether someone gains a party attachment from one observation to the next. The second is restricted to those who did have a party attachment at the previous time point, and therefore looks at whether someone sustains having a party attachment from one time point to the next.

We show different models according to sets of variables that capture our different theories of the ethnic partisanship gap. For each of the three samples, we also present a baseline model where the only covariate is ethnic group, in order to see how much of the difference is accounted for by each theory. We present average marginal effects of covariates, which can be compared across non-nested models, and significant coefficients at the 5\% level are indicated using bold type. Full tables of odds ratios and standard errors can be found in the appendix. We do not include parental socioeconomic controls in the other models because previous research has found that the demographic predictors of partisan preference and political engagement among minorities differ from those among the general population (Heath et al., 2013), so we would risk mis-specifying our models if we included these controls and assumed that the effect was the same across groups. 


\section{Results}

As we established in the introduction, there is a gap in levels of party identification between minority and white UK respondents when voters enter the electorate. In $2011-12,75 \%$ of $16-24$ ethnic minority young people report having a party preference, compared with $64 \%$ of white UK respondents of the same age. We also see this difference when we look at the percentage of young people who state any party attachment by ethnic group in the Understanding Society youth sample (Table 1). All the nonwhite minority groups have party attachment levels of between $56 \%$ and $67 \%$, around 25 percentage points higher than the white UK youth in the sample. White other is the minority group that shows a different relationship, with even lower levels of party attachment than the white UK. White other is a heterogeneous group, generally comprising parents from non-UK EU countries, which have different historical and contemporary attachments to the British party system. Young people of mixed heritage are more likely to have a party attachment than white UK young people, but less than other minority groups.

\section{Initial Acquisition of party attachment}

In the first set of models, we look at the predictors of having a party attachment at the time of the first observation of a respondent. The first question we aim to answer is whether the ethnic party attachment premium is actually an ethnic political interest premium. In other words, instead of party attachment, should we be trying to explain why minority respondents are more interested in politics? Table 2 shows the average marginal effect of belonging to different ethnic minority groups gaining a party attachment by the time of their first observation in our sample before and after adjusting for political interest. The results show that, unsurprisingly, politically interested young people are more likely to have developed a partisan attachment by the time they enter our sample. However, substantial differences remain once political interest is accounted for. These findings therefore suggest that the ethnic partisanship gap consists of more than just differences in political attention. 
Table 2: Logistic regression model of party attachment among 10-15 year olds (political interest predictors). Average marginal effects are reported, with significant coefficients at the 5\% level indicated in bold. Data: Understanding Society.

\begin{tabular}{lrr}
\hline & $\begin{array}{r}\text { Base model } \\
\text { AME }\end{array}$ & With political interest \\
& & \\
\hline white UK (ref.) & -0.09 & -0.12 \\
white other & $\mathbf{0 . 1 2}$ & 0.05 \\
Indian & $\mathbf{0 . 1 7}$ & $\mathbf{0 . 1 1}$ \\
Pakistani & $\mathbf{0 . 2 2}$ & $\mathbf{0 . 1 4}$ \\
Bangladeshi & $\mathbf{0 . 2 6}$ & $\mathbf{0 . 2 0}$ \\
black Caribbean & $\mathbf{0 . 1 9}$ & $\mathbf{0 . 1 2}$ \\
black African & $\mathbf{0 . 1 1}$ & 0.06 \\
mixed & & \\
not interested (ref) & & $\mathbf{0 . 3 9}$ \\
fairly & & $\mathbf{0 . 5 4}$ \\
very & 5292 & 5292 \\
\hline Number of observations & & \\
\hline
\end{tabular}

Table 3 includes various political predictors of a respondent having a party attachment at the time of their first observation. The results show that a number of aspects of a young person's partisan environment are associated with a greater level of party attachment when the respondent is first observed. Parental party identification is strongly associated with greater acquisition of initial party attachment. Children who are brought up in a two-parent household where both parents have a party identification are 11 to 13 percentage points more likely to have a party attachment when they are first observed in our data (compared with children brought up by a single parent without a party identification). Interestingly, party attachment does not seem to be reduced by political disagreement between parents. Young people who are exposed to parents with different party IDs actually have a higher level of party attachment acquisition than young people who are exposed to parents with the same partisanship (although the difference between these two types of households is not significant). This suggests that it may be exposure to politics and political matters that is important to developing a party attachment rather than exposure to one consistent political message. Consistent with this, we find that several other measures of parental political engagement predict developing a party attachment: mother's political interest, mother's certainty that she will vote, the difference between highest and lowest party like score of the mother, and the mother reporting that her political beliefs are important to her identity. 
Another factor that might explain some of the difference between minority and majority young people is that minorities are disproportionately raised in Labour areas. If the socialisation pressures are different in Labour areas (due to the area's social composition or the importance of partisanship to Labour supporters), then this might explain the difference between ethnic groups. Labour is by far the most popular party identity among white UK young people too, so Labour areas may be more conducive to gaining a political identity for young people in general. Our results do show a significant difference between Labour seats and other areas, with an average marginal effect of 6 percentage points between young people in Labour seats and those elsewhere.

After including these other predictors, the average marginal effects of each ethnic minority group shrink substantially, although the difference between the ethnicity coefficients in the new model and the original does not itself reach statistical significance. 
Table 3: Logistic regression model of party attachment among 10-15 year olds (political socialisation predictors). Average marginal effects are reported, with significant coefficients at the 5\% level indicated in bold. Data: Understanding Society.

\begin{tabular}{lr}
\hline & $\begin{array}{r}\text { Political } \\
\text { environment } \\
\end{array}$ \\
AME \\
\hline Age 10 (ref.) & 0.001 \\
Age 11 & 0.04 \\
Age 12 & 0.04 \\
Age 13 & $\mathbf{0 . 1 1}$ \\
Age 14 & 0.04 \\
Age 15 & \\
white UK (ref.) & -0.09 \\
white other & 0.06 \\
Indian & $\mathbf{0 . 1 2}$ \\
Pakistani & $\mathbf{0 . 1 7}$ \\
Bangladeshi & $\mathbf{0 . 2 4}$ \\
black Caribbean & 0.11 \\
black African & $\mathbf{0 . 0 8}$ \\
mixed & $\mathbf{- 0 . 0 8}$ \\
Female & \\
1 parent no party ID (ref.) & 0.03 \\
1 parent 1 party ID & -0.04 \\
2 parents no party ID & 0.02 \\
2 parents 1 party ID & $\mathbf{0 . 1 1}$ \\
2 parents 2 party IDs the same & $\mathbf{0 . 1 3}$ \\
2 parents 2 party IDs different & 0.05 \\
2 parents don't observe both parents & 0.003 \\
Mother's highest party like score & \\
Difference between mother's highest & $\mathbf{0 . 0 1}$ \\
and lowest party like score & $\mathbf{0 . 0 2}$ \\
Mother's strength of political identity & $\mathbf{0 . 0 4}$ \\
Mother's political interest & 0.02 \\
Mother's satisfaction in voting & $\mathbf{0 . 0 6}$ \\
Labour seat & 0.01 \\
Mother's duty to vote & $\mathbf{0 . 0 1}$ \\
Mother's satisfaction with democracy & -0.02 \\
Mother's certainty to vote & 5292 \\
Wave 5 & \\
Wave 7 & \\
Number of observations & \\
\hline & \\
&
\end{tabular}

The next factors we consider are socioeconomic differences between ethnic groups. Table 4 shows that being raised in a family with more educated parents is associated with higher levels of initial acquisition of party attachment. Having a mother in a lower supervisory or semi-routine and routine occupation or a father not in the household is associated with lower likelihood of having a party attachment - but the other economic activity and social class variables are insignificant. The effects of including these variables has different effects on the ethnic gap for different minority 
groups. For respondents from several of the ethnic minority groups that fare worse in the labour market and poverty status (Heath and Cheung, 2006; Fisher and Nandi, 2015; Li and Heath, 2018) (Pakistani, Bangladeshi and Black Caribbean), the inclusion of socioeconomic controls actually increases the minority partisanship gap. Working class voters have been the group most likely to become disengaged with party politics during the past few decades (Evans and Tilley, 2017), but as ethnic minority workers (the parents in our models) are over-represented in these occupations, this model suggests that higher levels of party attachment among young minorities is even more remarkable. Likewise, for Indians and black Africans, both ethnic groups that have high proportions of degree-holders, the minority gap does not notably expand after the inclusion of socioeconomic controls. This fits with the argument of Heath et al. (2011) that the social bases of partisanship are different for white UK and ethnic minority voters, and that consequently socioeconomic variables do not explain the differences between them.

Table 4: Logistic regression model of party attachment among 10-15 year olds (socioeconomic predictors). Average marginal effects are reported, with significant coefficients at the 5\% level indicated in bold. Data: Understanding Society.

\begin{tabular}{lr}
\hline & $\begin{array}{r}\text { Socioeconomic } \\
\text { factors } \\
\text { AME }\end{array}$ \\
\hline Age 10 (ref.) & \\
Age 11 & -0.001 \\
Age 12 & 0.04 \\
Age 13 & 0.04 \\
Age 14 & $\mathbf{0 . 1 1}$ \\
Age 15 & 0.05 \\
white UK (ref.) & \\
white other & -0.07 \\
Indian & 0.11 \\
Pakistani & $\mathbf{0 . 2 0}$ \\
Bangladeshi & $\mathbf{0 . 2 5}$ \\
black Caribbean & $\mathbf{0 . 2 9}$ \\
black African & $\mathbf{0 . 1 9}$ \\
mixed & 0.07 \\
Female & $\mathbf{- 0 . 0 8}$ \\
Mother has post-secondary education & \\
(ref.) & \\
Mother has school qualifications & $\mathbf{- 0 . 0 5}$ \\
Mother has other qualifications & -0.07 \\
Mother has no qualifications & -0.04 \\
Mother's data missing & -0.11
\end{tabular}


Father has post-secondary education

(ref.)

Father has school qualifications $\quad-0.05$

Father has other qualifications $\quad-0.05$

Father has no qualifications $\quad \mathbf{- 0 . 1 2}$

$\begin{array}{ll}\text { Mother in work (ref.) } & -0.07 \\ \text { Mother unemployed } & -0.07\end{array}$

Mother economically inactive $\quad-0.07$

Mother's data missing $\quad 0.05$

Mother in management \&

professional occupation (ref.)

Mother in intermediate occupation $\quad-0.01$

Mother in small employer/own

account occupation $\quad-0.03$

Mother in lower supervisory

occupation

$-0.15$

Mother in semi-routine/routine

occupation $\quad \mathbf{- 0 . 0 7}$

Mother occupational class unavailable $\quad 0.03$

Father in work (ref.)

Father unemployed 0.04

Father economically inactive $\quad 0.04$

Not living with father $\quad \mathbf{- 0 . 0 7}$

Father's data missing $\quad-0.01$

Mother's age $\quad \mathbf{0 . 0 0 4}$

Wave $5 \quad \mathbf{- 0 . 1 3}$

Wave $7 \quad 0.003$

Number of observations $\quad 5292$

The final set of factors we consider in initial party attachment acquisition are factors relating to social capital. We look at factors that could be considered both bonding or bridging social capital, although there is more support for the idea that bonding social capital promotes ethnic minority political engagement (Fennema and Tillie, 1999; Fieldhouse and Cutts, 2008a; Heath et al., 2013). Table 5 shows the effects of parental social capital on the initial formation of party attachment. Parental membership of political, local and religious organizations are associated with greater formation of initial party attachment. Having a mother who belongs to a political organization is unsurprisingly the strongest predictor, with a 10 percentage point higher probability of having a party identity at the time of the first observation. This is in line with our previous findings that factors relating to exposure to politics seem to be the strongest predictors of initial partisan attachment. However, two measures of bonding social capital - the proportion of residents from the same ethnic group in the local area (Census 2011 lower super output area), and the proportion of the mother's 
friends from the same ethnic group appear to be unrelated to a young person's likelihood of having a party attachment.

As with demographic controls, the effect of controlling for social capital varies across different ethnic groups. The partisanship gap between white UK, and Pakistani and Bangladeshi respondents stay the same or increase after accounting for social capital variables (not a statistically significant change). By contrast, the Indian, black Caribbean, and black African marginal effects decline moderately (and the Indian and black African coefficients become non-significant). Overall, the evidence here does not suggest that differences in social capital explain the ethnic partisanship gap.

Table 5: Logistic regression model of party attachment among 10-15 year olds (social capital predictors). Average marginal effects are reported, with significant coefficients at the 5\% level indicated in bold. Data: Understanding Society.

\begin{tabular}{lr}
\hline & Social capital \\
\hline Age 10 (ref.) & AME \\
Age 11 & 0.001 \\
Age 12 & 0.04 \\
Age 13 & 0.05 \\
Age 14 & $\mathbf{0 . 1 2}$ \\
Age 15 & 0.05 \\
white UK (ref.) & \\
white other & -0.12 \\
Indian & 0.08 \\
Pakistani & $\mathbf{0 . 1 8}$ \\
Bangladeshi & $\mathbf{0 . 2 2}$ \\
black Caribbean & $\mathbf{0 . 2 4}$ \\
black African & 0.15 \\
mixed & 0.06 \\
Female & $\mathbf{- 0 . 0 8}$ \\
Mother member of political organization & $\mathbf{0 . 1 0}$ \\
Mother's membership of political organization missing data & -0.25 \\
Mother member of religious organization & $\mathbf{0 . 0 6}$ \\
Mother's membership of religious organization missing data & 0.26 \\
Mother member of local organization & $\mathbf{0 . 0 4}$ \\
Mother's membership of local organization missing data & -0.02 \\
\% residents in LSOA from same ethnic group & 0.0004 \\
Proportion of mother's friends from same ethnic group & -0.01 \\
Wave 5 & $\mathbf{- 0 . 1 2}$ \\
Wave 7 & 0.01 \\
\hline Number of observations & 5292 \\
\hline
\end{tabular}

How much of the ethnic party attachment gap is accounted for? 


\section{[FIGURE 2 ABOUT HERE]}

Figure 2 plots the average marginal effect of belonging to an ethnic minority group on having a party attachment across our baseline model (no other predictors), and the three substantive models. We use a binary indicator of ethnic minority status for illustration purposes, because the coefficients for each ethnic minority groups are all positive in every model. The social capital model and socioeconomic do not substantively change the average marginal effect, and the confidence intervals overlap substantially. However, the political environment reduces the average marginal effect from 14 percentage points to 9 percentage points.

\section{Transition models of Party attachment ages 10-15}

Now that we have modelled the initial acquisition of a party attachment, we move to the question of what happens next during the critical 10-15 age period. We run two separate models among respondents who had a party attachment in the previous wave and respondents who did not. Because of the significantly smaller sample size and greater data requirements, we use a more parsimonious model specification for the longitudinal models than we did in the previous section. Similarly, we use a binary indicatory of ethnic minority status (Indian, Pakistani, Bangladeshi, black Caribbean, black African, and mixed), compared to white UK young people. Although this is not ideal, we believe it is justified because the coefficients for different ethnic minority groups (including young people of mixed heritage) are all positive. We exclude white other young people from this analysis, because our previous analysis shows that this group does not have the same party attachment levels of other minority groups.

The baseline effect of ethnic minority status in a logistic regression model of party attachment acquisition and loss is positive. Minority young people without a party attachment at the previous time point are more likely to gain one compared with white UK respondents - the average marginal effect is 0.11 , or 11 percentage points. Likewise, those who already have a party attachment are also more likely to retain it at the next wave - the average marginal effect is 0.09 , or a gap of 9 percentage points. 
Table 6 shows the effects of including socioeconomic controls on the minority partisanship gap. Few of the parental socioeconomic controls show significant effects on partisanship acquisition or retention. For partisan retention, having an unemployed mother, and a father with other educational qualifications predict lower retention. For partisan acquisition, the only significant predictor is having a degree-educated mother as opposed to one with school qualifications. After including socioeconomic variables in the model, the ethnic minority partisanship acquisition gap grows, whilst that for retention grows (neither change is significant).

Table 6: Transition models of party attachment, socioeconomic factors. Average marginal effects are reported, with significant coefficients at the $5 \%$ level indicated in bold.

\begin{tabular}{lrr}
\hline & $\begin{array}{r}\text { Acquisition } \\
\text { AME }\end{array}$ & $\begin{array}{r}\text { Retention } \\
\text { AME }\end{array}$ \\
\hline white UK (ref.) & & \\
ethnic minority & $\mathbf{0 . 0 8}$ & $\mathbf{0 . 1 0}$ \\
Age & 0.02 & 0.02 \\
Female & -0.03 & -0.01 \\
Post-secondary qualifications: mother (ref.) & & \\
School qualifications: mother & $\mathbf{- 0 . 0 6}$ & -0.06 \\
Other qualifications: mother & -0.05 & -0.07 \\
No qualifications: mother & 0.03 & -0.02 \\
Post-secondary qualifications: father (ref.) & & \\
School qualifications: father & -0.03 & -0.04 \\
Other qualifications: father & -0.05 & $-\mathbf{0 . 1 3}$ \\
No qualifications: father & 0.02 & -0.06 \\
Not living with father & -0.05 & -0.07 \\
Father's educational data missing & 0.01 & 0.02 \\
In work: mother (ref.) & & \\
Unemployed: mother & -0.02 & $\mathbf{- 0 . 2 0}$ \\
Economically inactive: mother & 0.03 & -0.04 \\
Mother's age & 0.003 & 0.0002 \\
\hline Number of observations & 1444 & 1106 \\
\hline
\end{tabular}

We next show the effects of including measures of a respondent's political socialisation environment. Table 7 shows that all parents in a household having a party identity is associated with a significantly higher probability of both retaining an existing party attachment (11 percentage points higher) and gaining one if the respondent does not have one already ( 9 percentage points higher).

Table 7: Transition models of party attachment, household political environment. Average marginal effects are reported, with significant coefficients indicated in bold.

\begin{tabular}{llll} 
Acquisition & & \multicolumn{2}{c}{ Retention } \\
AME & AME & AME & AME \\
\hline
\end{tabular}




\begin{tabular}{lrrrr}
\hline white UK (ref.) & & & & \\
ethnic minority & $\mathbf{0 . 0 7}$ & 0.07 & $\mathbf{0 . 0 9}$ & $\mathbf{0 . 0 7}$ \\
Age & 0.02 & 0.02 & 0.02 & 0.02 \\
Female & -0.03 & -0.03 & -0.01 & -0.002 \\
At least 1 parent has no party ID (ref.) & & & & \\
All parents have party ID & $\mathbf{0 . 0 9}$ & 0.08 & 0.11 & $\mathbf{0 . 1 1}$ \\
2 parents don't observe both party IDs & 0.04 & $\mathbf{0 . 0 4}$ & $\mathbf{0 . 0 7}$ & 0.07 \\
Mother's highest party like score & 0.01 & 0.01 & -0.02 & $\mathbf{- 0 . 0 2}$ \\
Difference between highest and lowest party & & & & \\
like score for mother & 0.01 & 0.01 & 0.02 & 0.02 \\
Importance of political beliefs (mother) & 0.003 & 0.002 & 0.02 & 0.01 \\
Mother's likelihood of voting & $\mathbf{0 . 0 1}$ & 0.01 & $\mathbf{0 . 0 1}$ & $\mathbf{0 . 0 1}$ \\
Mother's political interest & $\mathbf{0 . 0 4}$ & $\mathbf{0 . 0 3}$ & 0.03 & 0.02 \\
Mother's civic duty & 0.00 & 0.00 & 0.01 & 0.01 \\
Labour seat & 0.04 & 0.04 & 0.04 & 0.04 \\
Not interested in politics (ref.) & & & & \\
Fairly interested & & 0.07 & & $\mathbf{0 . 1 6}$ \\
Very interested & & 0.14 & & $\mathbf{0 . 2 7}$ \\
\hline Number of observations & 1444 & 1444 & 1106 & 1106 \\
\hline
\end{tabular}

A factor that is consistently related to party attachment across all three samples is how certain the young person's mother is that she will vote at the next general election. Although the average marginal effect is small - 1 percentage point in the transition models - this question has a response scale from 0 to 10 . The marginal effect of moving from the $25^{\text {th }}$ to the $75^{\text {th }}$ percentile (from 5 to 10 , where 10 is very likely to vote) is 5 percentage points for acquisition, and 6 points for retention. This underlines importance of parental commitment to electoral politics for the development of party attachment among young people.

After including controls, there is a substantial reduction in the effect of belonging to an ethnic minority group, although this effect is still sizeable and significant. This suggests that the various political attitudes controls in these models partially account for the different in acquisition of a party attachment between minority and white UK respondents.

We additionally add respondent's own political interest at the previous time point to these models in Table 7 . The addition of political interest does not change the minority party attachment acquisition gap, but it does reduce the gap in retention, and this ethnic gap becomes statistically insignificant (although the difference in coefficients is not significant). This suggests that a portion of the minority retention gap for 10-15 year olds is due to the level of political interest they have established by the time they first enter the Understanding Society youth panel. 
We also look at the possible role of social capital in explaining minority and white UK differences in party attachment acquisition and retention (Table 8). The only significant predictor of acquiring a party attachment is mother's membership of a local organization (aside from ethnic minority status). Having a mother who is a member of a political or religious organization is associated with higher retention rates. However, after accounting for these social capital factors, the effect of being an ethnic minority is increased for both acquisition and retention (although the standard errors are quite large on this estimate, so we should be cautious about interpreting this change). This suggests that although parental social capital may be an important reason for differences in political participation between ethnic minority groups and white UK adults - in particular for explaining types of political mobilization (Maxwell, 2012) - it does not explain or account for the partisanship gap between minority and white UK young people.

Table 8: Transition models of party attachment; social capital factors. Average marginal effects are reported, with significant coefficients indicated in bold type.

\begin{tabular}{lrr}
\hline & Acquisition & Retention \\
& AME & AME \\
\hline white UK (ref.) & $\mathbf{0 . 2 3}$ & $\mathbf{0 . 1 8}$ \\
ethnic minority & 0.02 & 0.02 \\
Age & -0.03 & -0.01 \\
Female & 0.01 & $\mathbf{0 . 0 8}$ \\
Mother member of political organization & 0.15 & -0.66 \\
Mother's political membership data missing & 0.05 & $\mathbf{0 . 1 3}$ \\
Mother member of religious organization & 0.64 & 0.34 \\
Mother's religious membership missing & $\mathbf{0 . 1 1}$ & 0.05 \\
Mother member of local organization & -0.34 & 0.23 \\
Mother's local membership data missing & 0.001 & 0.00 \\
\% residents in LSOA from same ethnic group & 0.02 & -0.02 \\
Proportion of mother's friends from same ethnic group & 1444 & 1106 \\
\hline Number of observations & & \\
\hline
\end{tabular}

\section{Conclusions}

This paper establishes that although on aggregate there are few differences in the level of party attachment between the white UK and ethnic minority populations, there are in fact large differences when we consider different age groups. Ethnic minority adults aged 20-30 have comparable levels of partisanship to white UK adults aged 50. Young people in Britain have been gaining party identities at lower rates than ever before (Fieldhouse et al., 2018). However, one group of young people not only 
are politically engaged, but maintain levels of partisan attachments not seen among young people for many decades: ethnic minority young people. This has been missed in previous studies of both ethnic minority political behaviour (Heath et al. 2013), and of the partisan dealignment in general (Dalton, 1984; Mellon, 2016). As these young people become a greater part of the electorate, this raises the possibility that the decline of young people's partisanship overall will begin to slow. Our analysis therefore explores the political socialisation of 10-15 year olds in Britain from a variety of ethnic backgrounds.

Our results point to the importance of parental views of the major parties in socialising the next generation's party attachment. Because the parents of white UK young people are less likely than parents of minorities to have a party identity, hold strong participatory norms and be interested in politics, they are not sending strong signals about choosing a political party to support. By contrast, minorities are continuing to transmit strong signals about politics and the parties to their children. We do not think that this is because partisanship and partisan socialisation works differently for ethnic minority families - rather, it works in the same way, but the levels of partisanship are higher among ethnic minority parents.

In one sense these results simply push the question back one level. Rather than the question of why are young minorities so attached to political parties, our next question is why do older minority voters have stronger party attachments and differentiated views of the party compared with majority party voters? Ultimately the answer may trace back to the experiences of the first-generation immigrants and their experiences with the Labour and Conservative parties. Alternatively, the answer may lie in the current positioning of the parties with regards to issues that minority groups find important.

If we do see this as pushing the problem back one level, the adult data gives some insight into where the minority/majority gap might have occurred. The oldest groups of white UK respondents have similar levels of party attachment to the minority respondents of the same age. This suggests that the grandparents of the young people in our sample are probably the ones who first failed to socialise their children into strong party attachments which was exacerbated with the subsequent round of socialisation of the current generation. 
The same parental factors that appear to be important in explaining the difference between minorities and white UK respondents in terms of gaining a party attachment either initially or during the 3 to 5 year period where we track them in Understanding Society also explain much of the minority difference in retention of party attachment. While we have not fully explained the gap in minority partisanship retention, some of it does seem to be related to minority respondents' greater interest in politics by the time they enter the panel.

Future work should assess whether these changing socialisation mechanisms can explain not only the cross-sectional difference between majority and minority party attachments but also the striking decline in party attachments in the British population more generally. Our analysis leads us to believe that the most important factor in explaining minority/majority differences in party attachment are parental norms and partisanship. However, the individual-level stability of partisanship and political attitudes over time (Bartels, 2002; Prior, 2010) suggests that these may be quite hard to change. Therefore, both the minority gap in partisanship and the overall decline in the general population may remain for some time to come.

\section{Funding}

This work was supported by the Economic and Social Research Council; through Understanding Society at the University of Essex, grant number ES/K005146/1, and through the Research Centre on Micro-Social Change at the University of Essex, grant number ES/L009153/1.

\section{References}

Akhtar, P. (2012) 'British Muslim Political Participation: After Bradford', The Political Quarterly, 83(4), pp. 762-766.

Anwar, M. (1986) Race and Politics: Ethnic Minorities and the British Political System. London: Tavistock.

Back, L. and Solomos, J. (2002) Race, Politics and Social Change. Routledge.

Bartels, L. M. (2002) 'Beyond the running tally: Partisan bias in political perceptions', Political Behavior, 24(2), pp. 117-150. doi: 10.1023/A:1021226224601.

Bartle, J. (2003) 'Measuring party identification: An exploratory study with focus groups', Electoral Studies, 22(2), pp. 217-237. doi: 10.1016/S0261-3794(02)00013-6. 
Burgess, S. (2014) Understanding the success of London's schools, The Centre for Market and Public Organisation. 14/333.

Calhoun-Brown, A. (1996) 'African American Churches and Political Mobilization: The Psychological Impact of Organizational Resources ', Journal of Politics, 58(4), pp. 935-953.

Crockett, A. and Voas, D. (2006) 'Generations of Decline: Religious Change in 20th-Century Britain', Journal for the Scientific Study of Religion, 45(4), pp. 567-585.

Dalton, R. J. (1984) 'Cognitive Mobilization and Partisan Dealignment in Advanced Industrial Democracies', The Journal of Politics, 46(1), pp. 264-284.

Dawson, M. C. (1994) Behind the Mule: Race and Class in African-American Politics. Princeton: Princeton University Press.

Dinas, E. (2013) 'Why Does the Apple Fall Far from the Tree? How Early Political Socialization Prompts Parent-Child Dissimilarity', British Journal of Political Science, (2014), pp. 1-26. doi: 10.1017/S0007123413000033.

Dustmann, C., Frattini, T. and Theodoropoulos, N. (2010) Ethnicity and Second Generation Immigrants, CReAM: Discussion Paper Series. 04/10. doi: 10.1093/acprof:osobl/9780199587377.003.0016.

Evans, G. and Tilley, J. (2017) The New Politics of Class: The Political Exclusion of the British Working Class. Oxford University Press.

Fennema, M. and Tillie, J. (1999) 'Political participation and political trust in Amsterdam: Civic communities and ethnic networks', Journal of Ethnic and Migration Studies, 25(4), pp. 703-726.

Fieldhouse, E. et al. (2018) Electoral Shocks: The volatile voter in a turbulent world. Oxford University Press.

Fieldhouse, E. and Cutts, D. (2008a) 'Diversity, density and turnout: The effect of neighbourhood ethno-religious composition on voter turnout in Britain', Political Geography, 27(5), pp. 530-548.

Fieldhouse, E. and Cutts, D. (2008b) 'Mobilisation or marginalisation? Neighbourhood effects on Muslim electoral registration in Britain in 2001 ', Political Studies, 56(2), pp. 333-354.

Fieldhouse, E. and Cutts, D. (2016) 'Shared Partisanship, Household Norms and Turnout: Testing a Relational Theory of Electoral Participation', British Journal of Political Science, pp. 1-17. doi: $10.1017 /$ S0007123416000089.

Fiorina, M. P. (1981) Retrospective voting in American national elections. Yale University Press.

Fisher, P. and Nandi, A. (2015) Poverty Across Ethnic Groups Through Recession and Austerity, Joseph Rowntree Foundation Report.

Grasso, M. T. et al. (2017) 'Thatcher's Children, Blair's Babies, Political Socialization and Trickledown Value Change: An Age, Period and Cohort Analysis', British Journal of Political Science, pp. 1-20. doi: 10.1017/S0007123416000375.

Green, D., Palmquist, B. and Schickler, E. (2002) Partisan Hearts and Minds: Political Parties and the Social Identities of Voters. Yale University Press.

Heath, A. et al. (2011) 'Ethnic Heterogeneity in the Social Bases of Voting at the 2010 British General Election', Journal of Elections, Public Opinion \& Parties, 21(3), pp. 255-277.

Heath, A. et al. (2013) The Political Integration of Ethnic Minorities in Britain. Oxford: Oxford 
University Press.

Heath, A. and Cheung, S. Y. (2006) 'Ethnic penalties in the labour market: Employers and discrimination', Pensions, (341), p. 124.

Heath, O. (2016) 'Policy Alienation, Social Alienation and Working-Class Abstention in Britain, 1964-2010', British Journal of Political Science, 28(1), p. 121. doi: 10.1017/S0007123416000272.

Jivraj, S. and Khan, O. (2013) Ethnicity and deprivation in England: How likely are ethnic minorities to live in deprived neighbourhoods?, Dynamics of Diversity: Evidence from the 2011 Census.

Knies, G. (2017) Understanding Society: The UK Household Longitudinal Study Wave 1-7 User Guide.

Martin, N. S. (2016) Ethnic Minority Voters in 2015: A Breakthrough for the Conservative Party? Working paper available at https://papers.ssrn.com/sol3/papers.cfm?abstract_id=2881684

Maxwell, R. (2012) No Title, Integration Trade-Offs. Cambridge University Press.

McAndrew, S. and Voas, D. (2014) 'Immigrant generation, religiosity and civic engagement in Britain', Ethnic and Racial Studies. Taylor \& Francis, 37(1), pp. 99-119. doi:

10.1080/01419870.2013.808755.

Mellon, J. (2016) Party Attachment in Great Britain: Five Decades of Dealignment. Working paper available at https://papers.ssrn.com/sol3/papers.cfm?abstract_id=2745654

Nandi, A. and Platt, L. (2018) 'The relationship between political and ethnic identity among UK ethnic minority and majority populations.', Journal of Ethnic and Migration Studies.

ONS (2013) 2011 Census Analysis - comparing rural and urban areas of England and Wales, Office for National Statistics.

Prior, M. (2010) 'You've either got it or you don't? The stability of political interest over the life cycle', Journal of Politics, 72(3), pp. 747-766. doi: 10.1017/S0022381610000149.

Saggar, S. and Heath, A. (1999) 'Race: Towards a Multicultural Electorate?', in Evans, G. and Norris, P. (eds) Critical Elections: British Parties and Voters in Long-Term Perspective, pp. 102-23.

Sanders, D., Burton, J. and Kneesaw, J. (2002) 'Identifying the True Party Identifiers. A Question Wording Experiment’, Party Politics, 8(2), pp. 193-205. doi: 10.1177/1354068802008002003.

Sobolewska, M. et al. (2015) 'Understanding the effects of religious attendance on political participation among ethnic minorities of different religions', European Journal of Political Research, 54(2), pp. 271-287. doi: 10.1111/1475-6765.12081.

Tilley, J. (2002) 'Political Generations and Partisanship in the UK , 1964-1997', Journal of the Royal Statistical Society. Series A ( Statistics in Society ), 165(1), pp. 121-135.

Van Tubergen, F. and Sindradóttir, J. İ. (2011) 'The Religiosity of Immigrants in Europe: A CrossNational Study', Journal for the Scientific Study of Religion, 50(2), pp. 272-288. doi: 10.1111/j.14685906.2011.01567.x.

Wilson, J. M. (2012) 'How are we doing? Group-based economic assessments and African American political behavior', Electoral Studies, 31(3), pp. 550-561. 
Figure 1: Proportion of adults who state a party preference in the wave 3 Understanding Society data in 2011-2012. GAM smoothing with $95 \%$ confidence intervals shown.



Figure 2: The average marginal effect of ethnic minority status on party attachment across 4 different models.

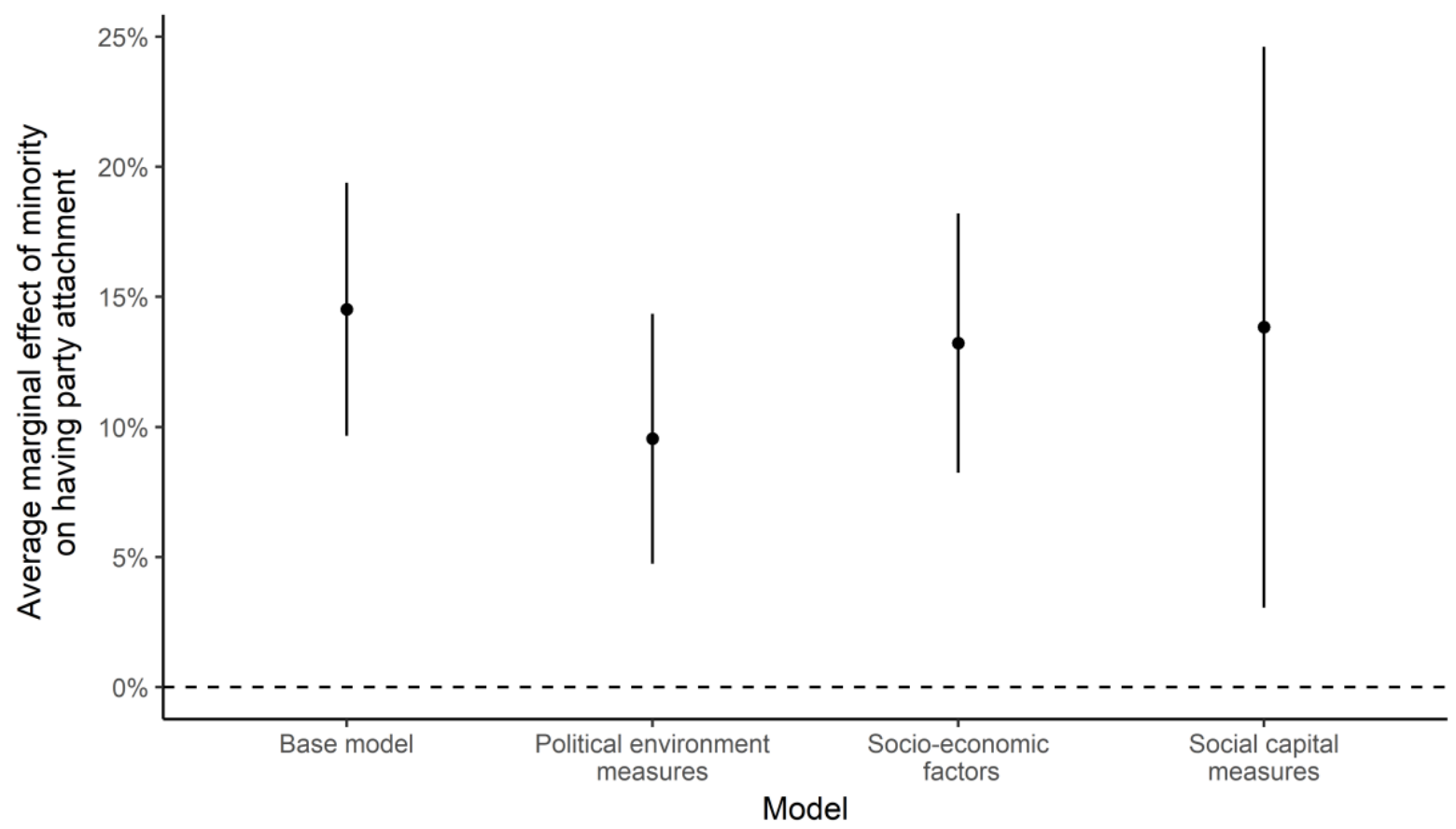

